\title{
Supramolecular hydrogen-bonding network in 1-(diaminomethylene)thiouron-1-ium 4-hydroxybenzenesulfonate crystal
}

\author{
Genivaldo J. Perpétuo ${ }^{\mathrm{a}}$, Rafael S. Gonçalves ${ }^{\mathrm{a}}$, Jan Janczak ${ }^{\mathrm{b}, *}$ \\ ${ }^{a}$ Departamento de Física, Instituto de Ciências Exatas e Biológicas, Universidade Federal de Ouro Preto, 35400-000 Ouro Preto, MG, Brazil \\ ${ }^{\mathrm{b}}$ Institute of Low Temperature and Structure Research, Polish Academy of Sciences, PO Box 1410, 50950 Wroctaw, Poland
}

\section{H I G H L I G H T S}

- Crystal of 1-(diaminomethylene) thiouron-1-ium 4-hydroxybenzenesulfonate was obtained.

- Hydrogen bonding motif $\mathrm{R}_{2}^{2}(8)$ of $1: 1$ forms supramolecular complex.

- The characteristic vibrational bands of the $\mathrm{H}$ and $\mathrm{D}$ analogue are discussed.

\section{A R T I C L E I N F O}

\section{Article history:}

Received 16 January 2015

Received in revised form 18 March 2015

Accepted 27 April 2015

Available online 6 May 2015

\section{Keywords:}

1-(diaminomethylene)thiouron-1-ium

4-hydroxybenzenesulfonate

Crystal structure

Hydrogen bonds

DFT calculations

Vibrational spectroscopy

\section{G R A P H I C A L A B S T R A C T}

The solid-state organisation of 1-(diaminomethylene) thiouron-1-ium 4-hydroxybenzenesulfonate has been analysed with respect to cation-anion and hydrogen bonding interactions. The oppositely charged units interact via hydrogen bonds with the graph of $\mathrm{R}_{2}^{2}(8)$.

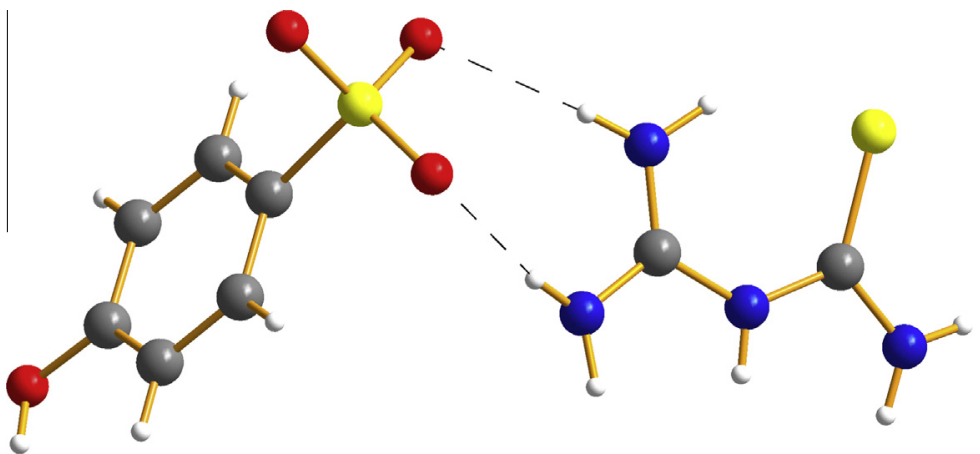

\section{A B S T R A C T}

The single crystals of 1-(diaminomethylene)thiouron-1-ium 4-hydroxybenzenesulfonate were grown using a solution growth technique. The compound crystallises in the centrosymmetric $P 2_{1} / c$ space group of the monoclinic system. The conformation of the 1-(diaminomethylene)thiouron-1-ium cation is not strictly planar, but twisted. Both arms of the cation are oppositely rotated by $8.5(1)^{\circ}$ around the $\mathrm{C}-\mathrm{N}$ bonds involving the central $\mathrm{N}$ atom. The arrangement of oppositely charged components, i.e. 1-(diamino methylene)thiouron-1-ium cations and 4-hydroxybenzenesulfonate anions in the crystal is mainly determined by ionic and hydrogen-bonding interactions forming supramolecular network. The possible hydrogen-bonding interactions between cation and anion units were analysed on the basis of molecular orbital calculations. The obtained deuterated analogue crystallises similar as H-compound in the monoclinic system $\left(P 2_{1} / c\right)$ with quite similar lattice parameters. The compound was also characterised by the FT-IR and Raman spectroscopies. The characteristic bands of the functional and skeletal groups of the protiated and deuterated analogue of 1-(diaminomethylene)thiouron-1-ium 4-hydroxybenzenesulfonate are discussed.

(c) 2015 Elsevier B.V. All rights reserved.

\footnotetext{
* Corresponding author.

E-mail address: j.janczak@int.pan.wroc.pl (J. Janczak).
} 
<smiles>CN/C(N)=N\O</smiles>

(a)<smiles>NC(=S)NC(N)=S</smiles>

(b)<smiles>O=S(=O)(O)c1ccc(O)cc1</smiles>

(c)

Scheme 1. 2-imino-4-thiobiuret (a) and it tautomeric form of 1-(diaminomethylene)-thiourea (b), and 4-hydroxybenzenesulfonic acid (c).

\section{Introduction}

Supramolecular chemistry and crystal engineering are closely related fields [1]. Both have been rapidly extending research area over the past two decades [2]. The non-covalent intermolecular interactions are of fundamental importance for understanding of molecular recognition and self-organisation supramolecular synthesis of new solids with designated architecture and desired physical and chemical properties [3]. A productive strategy in the crystal engineering is to build supramolecular structures from molecules containing complementary arrays of the hydrogen bonding sites [4]. The supramolecular synthon of recurring

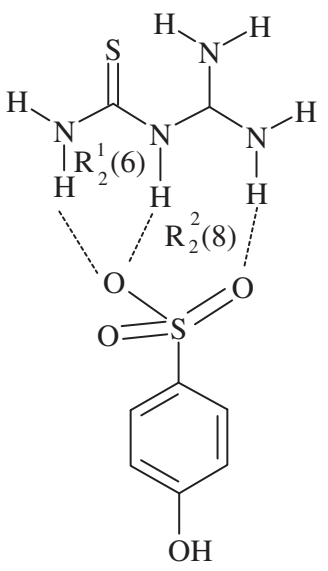

(a)<smiles>[R10]OS(=O)(=O)c1ccc(O)cc1</smiles>

(b)<smiles>[R10]OS(=O)(=O)c1ccc(O)cc1</smiles>

(c)<smiles>[R10]OS(=O)(=O)c1ccc(O)cc1</smiles>

(d)<smiles>[R10]COS(=O)(=O)c1ccc(O)cc1</smiles>

(e)<smiles>[R20]OS(=O)(=O)c1ccc(O)cc1</smiles>

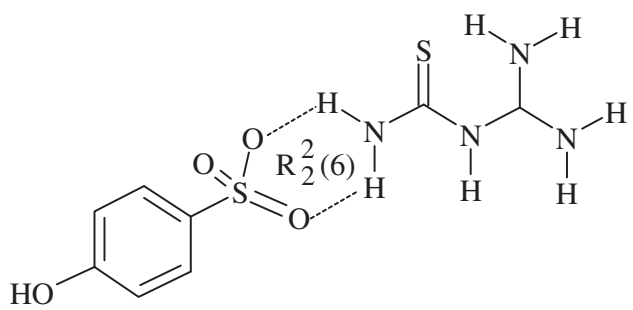

(g)<smiles>[R20]OS(=O)(=O)c1ccc(O)cc1</smiles>

Scheme 2. Possible hydrogen-bonding interactions between 1-(diaminomethylene)-thiouron-1-ium cation and 4-hydroxybenzenesulfonate anion with graphs $\mathrm{R}_{2}^{2}(8), \mathrm{R}_{2}^{1}(6)$ and $\mathrm{R}_{2}^{2}(6)$. 
Table 1

Crystallographic data for 1-(diaminomethylene)thiouron-1-ium 4-hydroxybenzenesulfonate.

\begin{tabular}{|c|c|}
\hline Empirical formula & $\left(\mathrm{C}_{2} \mathrm{H}_{7} \mathrm{~N}_{4} \mathrm{~S}\right)\left(\mathrm{C}_{6} \mathrm{H}_{4}(\mathrm{OH}) \mathrm{SO}_{3}\right)$ \\
\hline Formula weight $\left(\mathrm{g} \mathrm{mol}^{-1}\right)$ & 292.34 \\
\hline Crystal system, space group & Monoclinic, $P 2_{1} / c$ (No. 14) \\
\hline$a(\AA)$ & $5.646(1)$ \\
\hline$b(\AA)$ & 7.601(1) \\
\hline$c(\AA)$ & $29.405(5)$ \\
\hline$\beta\left({ }^{\circ}\right)$ & $93.66(2)$ \\
\hline$V\left(\AA^{3}\right)$ & $1259.3(4)$ \\
\hline$Z$ & 4 \\
\hline$D_{\text {calc }} / D_{\text {obs }}\left(\mathrm{g} \mathrm{cm}^{-3}\right)$ & $1.542 / 1.54$ \\
\hline$\mu\left(\mathrm{mm}^{-1}\right)$ & 0.436 \\
\hline Crystal size (mm) & $0.38 \times 0.32 \times 0.20$ \\
\hline Radiation type, wavelength, $\lambda(\AA)$ & Mo $K \alpha, 0.71073$ \\
\hline Temperature (K) & 295(2) \\
\hline$\theta$ range $\left(^{\circ}\right)$ & $3.01-29.40$ \\
\hline Absorption correction & Numerical, CrysAlis Red [10] \\
\hline$T_{\min } / T_{\max }$ & $0.8526 / 0.9191$ \\
\hline Reflections collected/unique/observed & $13522 / 3015 / 2004$ \\
\hline$R_{\text {int }}$ & 0.0248 \\
\hline Refinement on & $F^{2}$ \\
\hline$R\left[F^{2}>2 \sigma\left(F^{2}\right)\right]$ & 0.0336 \\
\hline$w R\left(F^{2}\right.$ all reflections $)$ & 0.0699 \\
\hline Goodness-of-fit, $S$ & 1.002 \\
\hline$\Delta \rho_{\max }, \Delta \rho_{\min }\left(\mathrm{e} \AA^{-3}\right)$ & $+0.161,-0.223$ \\
\hline
\end{tabular}

hydrogen-bonding pattern is an effective approach for structural design of solids [5].

The commercially available 2-imino-4-thiobiuret (Aldrich, CAS No. 2114-20-05) is, as has been shown by the X-ray single crystal analysis [6], the tautomeric form of 1-(diaminomethylene)thiourea (Scheme 1). Both tautomers are already considered to be useful building blocks in crystal engineering, since they contain hydrogen-bonding sites. Additionally, both tautomers can act as $\mathrm{N}, \mathrm{N}$ - or $\mathrm{N}, \mathrm{S}$-coordinating ligands forming several types of complexes with metal ions [7].

The 1-(diaminomethylene)-thiourea contains the basic $\mathrm{N}$ atom with the lone pair of electrons, therefore it can forms salts with organic and inorganic acids forming extended hydrogen-bonding networks in solids [8]. In particular, the supramolecular aggregation pattern of 1-(diaminomethylene)-thiourea with tartaric acid and its deuterated analogue are examples of supramolecular hydrogen-bonding networks in solids that can be utilised as materials for non-linear optics [9].

In the present work, we investigate the supramolecular architecture formed by self-assembly of 1-(diaminomethylene)-thiourea with 4-hydroxybenzenesulfonic acid (Scheme 1c). This study is aimed into the interactions between oppositely charged units, i.e. 1-(diaminomethylene)-thiouron-1-ium cations and 4-hydroxybenzenesulfonate anions, and the formation of the supramolecular structure. The possible hydrogen-bonding interaction between 1-(d iaminomethylene)-thiouron-1-ium cation and 4-hydroxybenzenesulfonate anion with different graphs illustrates Scheme 2. The

Table 2

Selected bond lengths $(\AA)$ and angles $\left(^{\circ}\right)$ for 1-(diaminomethylene)thiouron-1-ium 4hydroxy-benzenesulfonate.

\begin{tabular}{llll}
\hline $\mathrm{S} 1-\mathrm{C} 1$ & $1.6716(15)$ & $\mathrm{C} 1-\mathrm{N} 2$ & $1.3107(19)$ \\
$\mathrm{C} 1-\mathrm{N} 1$ & $1.3831(19)$ & $\mathrm{N} 1-\mathrm{C} 2$ & $1.3621(18)$ \\
$\mathrm{C} 2-\mathrm{N} 3$ & $1.3032(19)$ & $\mathrm{C} 2-\mathrm{N} 4$ & $1.2950(20)$ \\
$\mathrm{S} 2-\mathrm{C} 3$ & $1.7579(14)$ & $\mathrm{S} 2-\mathrm{O} 1$ & $1.4438(11)$ \\
$\mathrm{S} 2-\mathrm{O} 2$ & $1.4643(10)$ & $\mathrm{S} 2-\mathrm{O} 3$ & $1.4554(11)$ \\
$\mathrm{N} 2-\mathrm{C} 1-\mathrm{N} 1$ & $112.81(13)$ & $\mathrm{N} 4-\mathrm{C} 2-\mathrm{N} 3$ & $121.64(16)$ \\
$\mathrm{N} 2-\mathrm{C} 1-\mathrm{S} 1$ & $122.00(13)$ & $\mathrm{N} 4-\mathrm{C} 2-\mathrm{N} 1$ & $121.14(16)$ \\
$\mathrm{N} 1-\mathrm{C} 1-\mathrm{S} 1$ & $125.15(11)$ & $\mathrm{N} 3-\mathrm{C} 2-\mathrm{N} 1$ & $117.21(14)$ \\
$\mathrm{C} 2-\mathrm{N} 1-\mathrm{C} 1$ & $130.85(13)$ & & \\
\hline
\end{tabular}

compound was also characterised by vibrational spectroscopy, and the results are discussed and compared with the data obtained for a neutral 1-(diaminomethylene)-thiourea molecule.

\section{Experimental}

All materials were commercially available and used as received. Elemental analysis was carried out with a Perkin-Elmer 240 elemental analyser.

Preparation of 1-(diaminomethylene)thiouron-1-ium 4hydroxybenzenesulfonate and its deuterated $D^{8}$ analogue

Commercially available 2-imino-4-thiobiuret (Aldrich, CAS No. 2114-02-05), which is in fact the tautomeric form 1-(diaminomethylene)thiourea and the 4-hydroxybenzenesulfonic acid were added to hot water in a molar proportion of $1: 1$. When the solution became homogeneous it was cooled slowly and kept at room temperature. After several days, transparent colourless crystals of $\mathrm{C}_{6} \mathrm{H}_{4}(\mathrm{OH}) \mathrm{SO}_{3} \cdot \mathrm{C}_{2} \mathrm{H}_{7} \mathrm{~N}_{4} \mathrm{~S}$ were formed. Analysis: calculated for $\mathrm{C}_{8} \mathrm{H}_{12} \mathrm{~N}_{4} \mathrm{~S}_{2} \mathrm{O}_{4}$ : C, 32.86; N, 19.17; O, 21.89; S, 21.94 and $\mathrm{H}, 4.14 \%$. Found: C, 32.66; N, 19.10; O, 22.04; S, 22.09 and H, 4.09\%. Deuterated $\mathrm{d}^{8}$ analogue of 1-(diaminomethylene)thiouron-1-ium 4-hydroxybenzenesulfonate was prepared by the usual reaction with heavy water. The crystals of 1-(diaminomethylene)thiouro n-1-ium 4-hydroxybenzenesulfonate were dissolved in heavy water, and left in the atmosphere saturated with heavy water for one weak, in order to avoid the contamination of the crystals. The procedure was repeated twice.

\section{X-ray data collection}

X-ray intensity data for the crystals were collected using graphite monochromatic Mo K $\alpha$ radiation on a four-circle $\kappa$ geometry KUMA KM-4 diffractometer with a two-dimensional area CCD detector. The $\omega$-scan technique with $\Delta \omega=1.0^{\circ}$ for each image was used for data collection. The 930 images for six different runs covering over $99 \%$ of the Ewald sphere were performed. One image was used as a standard after every 50 images for monitoring of the crystal stability and the data collection. No correction on the relative intensity variations was necessary. Data collections were made using the CrysAlis CCD program [10]. Integration, scaling of the reflections, correction for Lorentz and polarisation effects and absorption corrections were performed using the CrysAlis Red program [10]. The structures were solved by the direct methods using SHELXS-97 and refined using SHELXL-97 program [11]. The hydrogen atoms involving in the hydrogen bonds were located in difference Fourier maps and were refined. The hydrogen atoms joined to aromatic carbon atoms were introduced in their geometrical

Table 3

Hydrogen-bond geometry $\left(\AA,^{\circ}\right)$ for 1-(diaminomethylene)thiouron-1-ium 4-hydroxybenzenesulfonate.

\begin{tabular}{lllll}
\hline $\mathrm{D}-\mathrm{H} \cdots \mathrm{A}$ & $\mathrm{D}-\mathrm{H}$ & $\mathrm{H} \cdots \mathrm{A}$ & $\mathrm{D} \cdots \mathrm{A}$ & $\mathrm{D}-\mathrm{H} \cdots \mathrm{A}$ \\
\hline $\mathrm{N} 1-\mathrm{H} 1 \cdots \mathrm{O}^{\mathrm{a}}$ & $0.80(2)$ & $2.27(2)$ & $3.016(2)$ & $155(2)$ \\
$\mathrm{N} 2-\mathrm{H} 2 \cdots \mathrm{S}^{\mathrm{b}}$ & $0.90(2)$ & $2.53(2)$ & $3.414(2)$ & $168(2)$ \\
$\mathrm{N} 2-\mathrm{H} 3 \cdots 3^{\mathrm{a}}$ & $0.84(2)$ & $2.23(2)$ & $2.994(2)$ & $153(2)$ \\
$\mathrm{N} 3-\mathrm{H} 4 \cdots \mathrm{O} 1$ & $0.85(2)$ & $2.08(2)$ & $2.921(2)$ & $170(2)$ \\
$\mathrm{N} 3-\mathrm{H} 5 \cdots \mathrm{O} 2^{\mathrm{a}}$ & $0.88(2)$ & $2.01(2)$ & $2.880(2)$ & $172(2)$ \\
$\mathrm{N} 4-\mathrm{H} 6 \cdots \mathrm{O} 3$ & $0.86(2)$ & $2.17(2)$ & $3.018(2)$ & $169(2)$ \\
$\mathrm{N} 4-\mathrm{H} 7 \cdots \mathrm{S} 1$ & $0.93(2)$ & $2.20(2)$ & $2.988(2)$ & $141(2)$ \\
$\mathrm{O} 4-\mathrm{H} 44 \cdots \mathrm{O} 2^{\mathrm{c}}$ & $0.82(2)$ & $1.94(2)$ & $2.732(2)$ & $162(2)$ \\
\hline
\end{tabular}

Symmetry codes.

$x, y+1, z$.

b $-x-1,-y+2,-z+1$.

c $-x+1, y+1 / 2,-z+1 / 2$. 
Table 4

Difference between the energies of most stable hydrogen-bonded unit $c$ and the other units of 1-(diaminomethylene)-thiouron-1-ium cation and 4-hydroxybenzenesulfonate anion.

\begin{tabular}{ll}
\hline Hydrogen bonded units as in Scheme 2 & $\Delta E\left(\mathrm{~kJ} \mathrm{~mol}^{-1}\right)$ \\
\hline$a$ & 0 \\
$b$ & 2.03 \\
$c$ & 6.88 \\
$d$ & 7.03 \\
$e$ & 6.72 \\
$f$ & 70.10 \\
$g$ & 69.22 \\
$h$ & 70.08
\end{tabular}

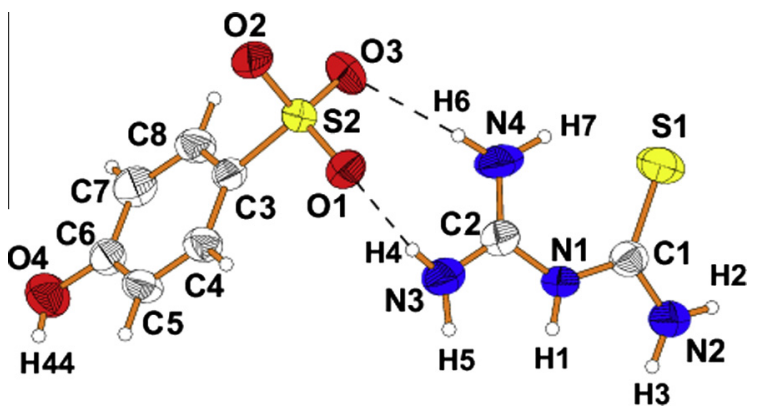

Fig. 1. View of 1-(diaminomethylene)thiouron-1-ium 4-hydroxybenzenesulfonate showing displacement ellipsoids at the $50 \%$ probability level and $\mathrm{H}$ atoms as a sphere of arbitrary radii. Dashed lines represent the hydrogen bonds.

positions. The final difference Fourier maps showed no peaks of chemical significance. Details of the data collection parameters, crystallographic data and final agreement parameters are collected in Table 1. Visualisations of the structures were made with the Diamond 3.0 program [12]. Selected geometrical parameters are listed in Table 2 and the geometry of hydrogen bonding interactions is collected in Table 3. The obtained deuterated analogue crystallises similar as $\mathrm{H}$-compound in monoclinic system $\left(P 2_{1} / c\right)$ with quite similar lattice parameters.

\section{Vibrational spectra measurements}

The vibrational measurements of $\mathrm{H}$-compound and its deuterated $\left(D^{8}\right)$ analogue were carried out at room temperature. The Fourier transform infrared spectrum was recorded from nujol mulls between 4000 and $400 \mathrm{~cm}^{-1}$ on a Bruker IFS 113 V FTIR spectrometer. Resolution was set up to $2 \mathrm{~cm}^{-1}$. The Fourier Transform Raman spectrum was recorded on a FRA-106 attached to the Bruker 113 V FTIR spectrometer equipped with Ge detector cooled to liquid nitrogen temperature. Resolution was set up to $2 \mathrm{~cm}^{-1}$, signal/noise ratio was established by 32 scans. $\mathrm{Nd}^{3+}-\mathrm{YAG}$ air-cooled diode pumped laser of power ca. $200 \mathrm{~mW}$ was used as an exciting source. The incident laser excitation was $1064 \mathrm{~nm}$. The scattered light was collected at the angle of $180^{\circ}$ in the region of $3600-80 \mathrm{~cm}^{-1}$, resolution $2 \mathrm{~cm}^{-1}, 256$ scans.

\section{Theoretical calculation}

Theoretical calculations with geometry optimisation of possible hydrogen-bonding interaction between 1-(diaminomethyle ne)-thiouron-1-ium cation and 4-hydroxybenzenesulfonate anion with different graphs illustrated in Scheme 2 were performed with Gaussian09 program package [13]. All calculations were carried out with the DFT method using the Becke3-Lee-Yang-Parr correlation functional (B3LYP) [14-16] with the $3-21+G^{*}$ basis set. As convergence criterions the threshold limits of 0.00045 and

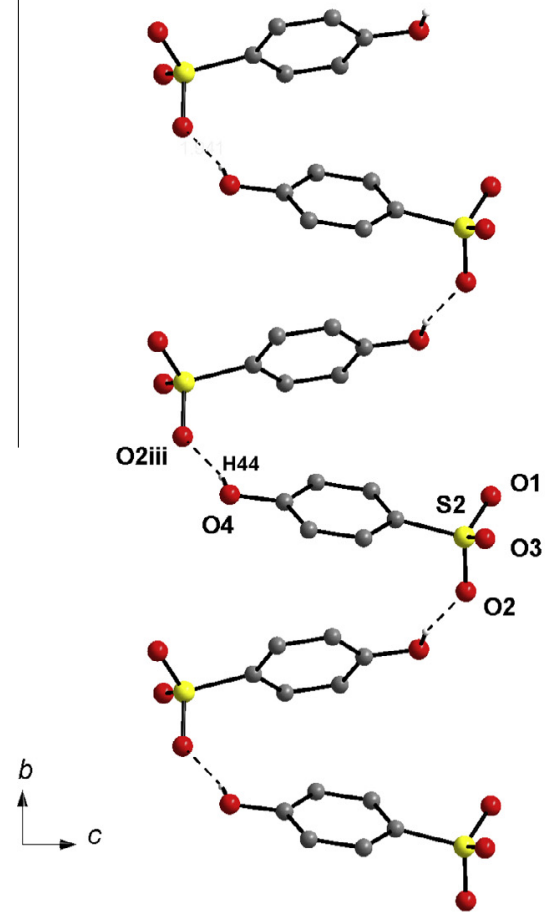

(a)

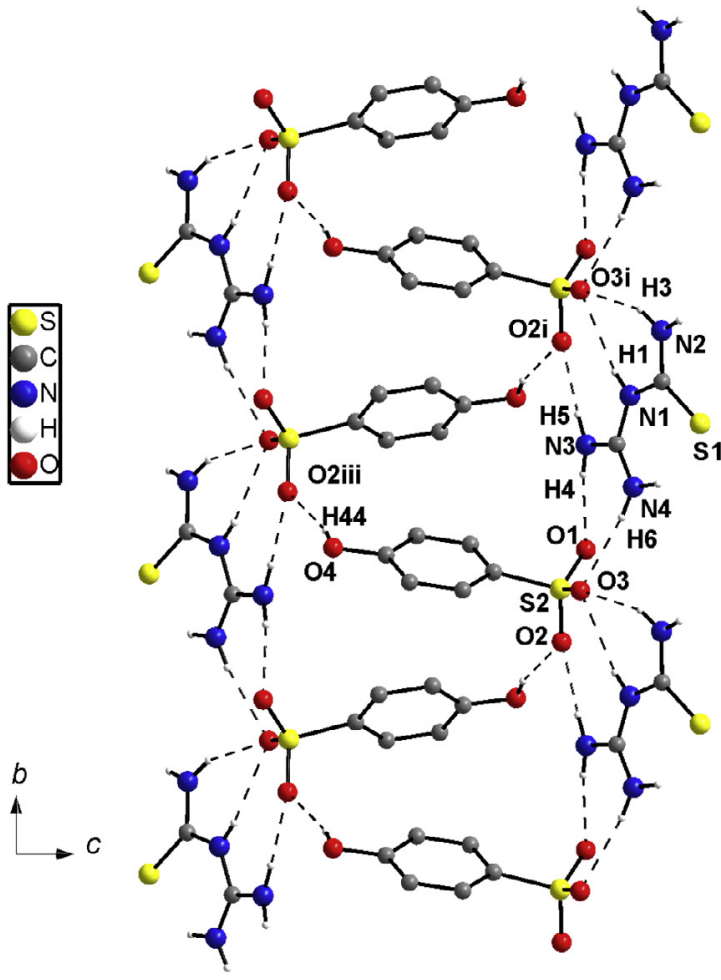

(b)

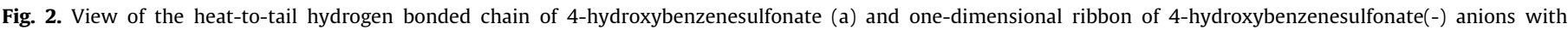
assistance of 1-(diaminomethylene)thiouron-1-ium cations (b). 


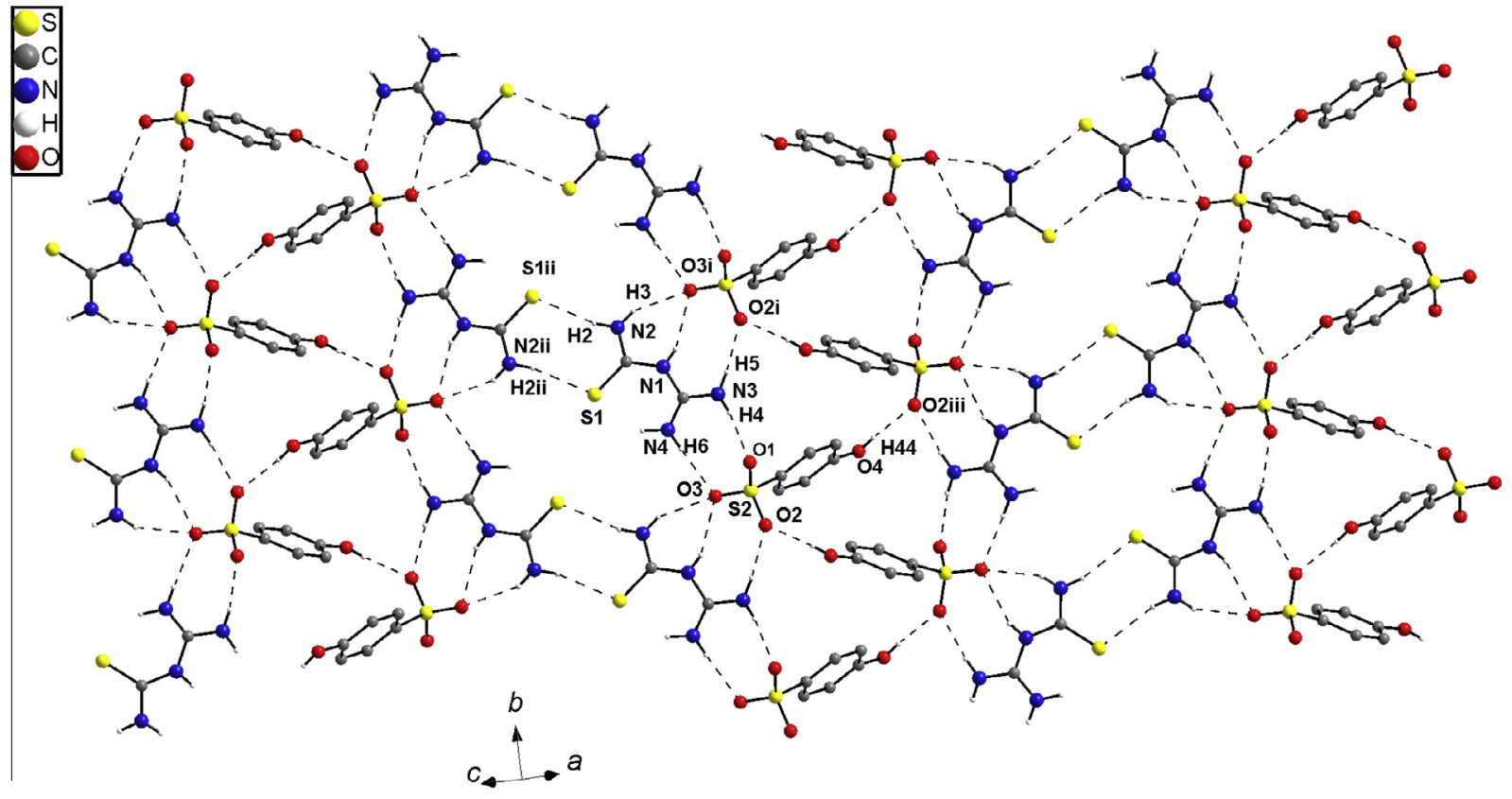

(a)

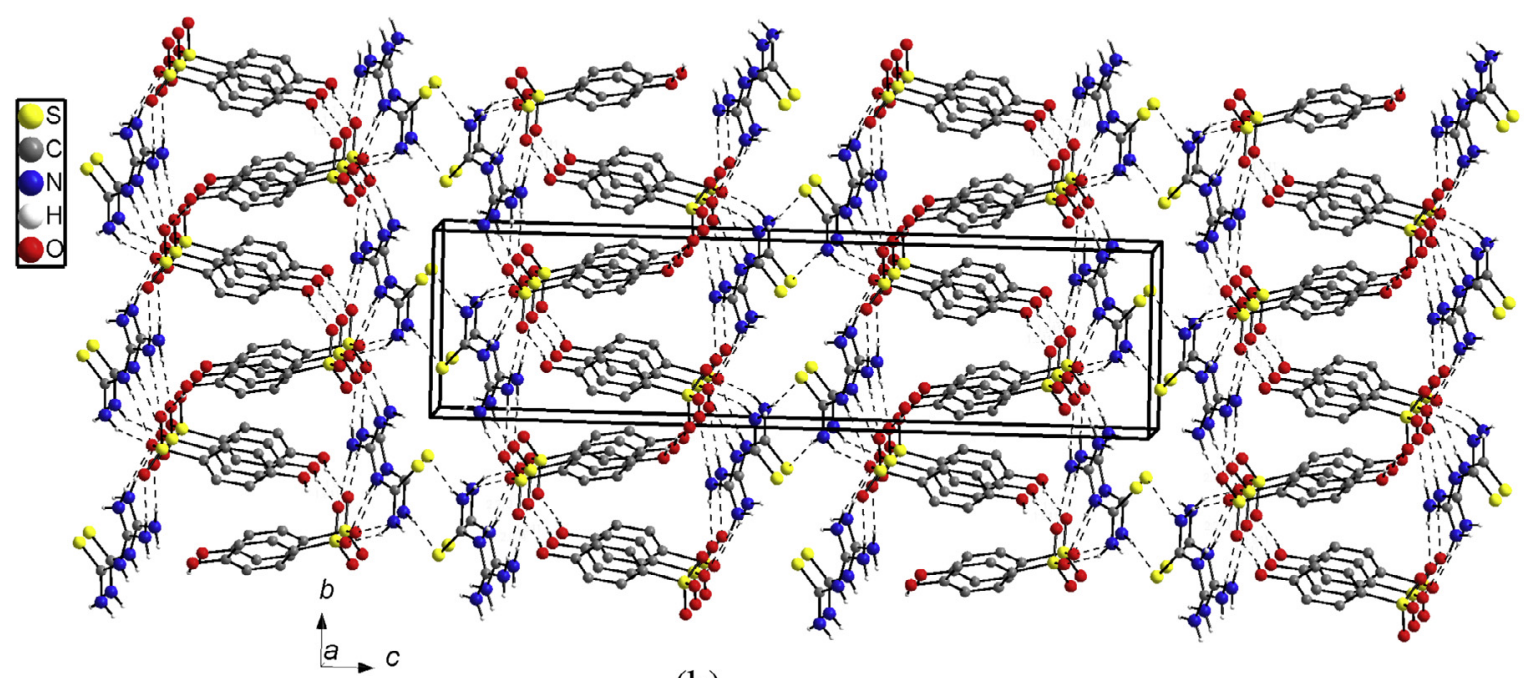

(b)

Fig. 3. View of two-dimensional supramolecular layer (a) and the crystal packing of 1-(diaminomethylene)thiouron-1-ium 4-hydroxybenzenesulfonate (b).

0.0018 a.u. were applied for the maximum force and the displacement, respectively. Energies were calculated for optimised geometries of hydrogen-bonded units of 1-(diaminomethylene)thiouron-1-ium cation and 4-hydroxybenzenesulfonate anion. The difference between the energy of most stable hydrogen-bonded unit a (see Scheme 2) and the energy of the other hydrogen-bonded units of 1-(diaminomethylene)-thiouro n-1-ium cation and 4-hydroxybenzenesulfonate anion are listed in Table 4.

\section{Results and discussion}

Good quality single crystals of 1-(diaminomethylene) thiouron-1-ium 4-hydroxybenzenesulfonate suitable for the X-ray single crystal analysis were obtained from water solutions at ambient temperature. The 1-(diaminomethylene) thiouron-1-ium 4-hydroxybenzenesulfonate crystallises in the centrosymmetric space group $P 2_{1} / c$ of monoclinic system. The deuterated $D^{8}$ analogue was obtained by usual reaction of protiated crystals with heavy water. The deuterated analogue also crystallises in the monoclinic system $\left(P 2_{1} / c\right)$ with quite similar lattice parameters, so both protiated and deuterated crystals of 1-(diaminomethylene) thiouron-1-ium 4-hydroxybenzenesulfonate are isostructural.

The X-ray single crystal analysis of 1-(diaminomethylene) thiouron-1-ium 4-hydroxybenzenesulfonate shows that the sulfonate group is deprotonated, and the proton is transferred to the central N1 atom of 1-(diaminomethylene) thiourea molecule forming 1-(diaminomethylene) thiouron-1-ium cation. The oppositely charged units interact via two almost linear hydrogen bonds with a graph of $\mathrm{R}_{2}^{2}(8)$ forming molecular complex as illustrate Fig. 1 . The $\mathrm{R}_{2}^{2}(8)$ motif is formed by donation to the sulfonate group of 4-hydroxybenzenesulfonate anion from the amino groups bonded to the $\mathrm{C} 2$ atom as shows Scheme 2e. 


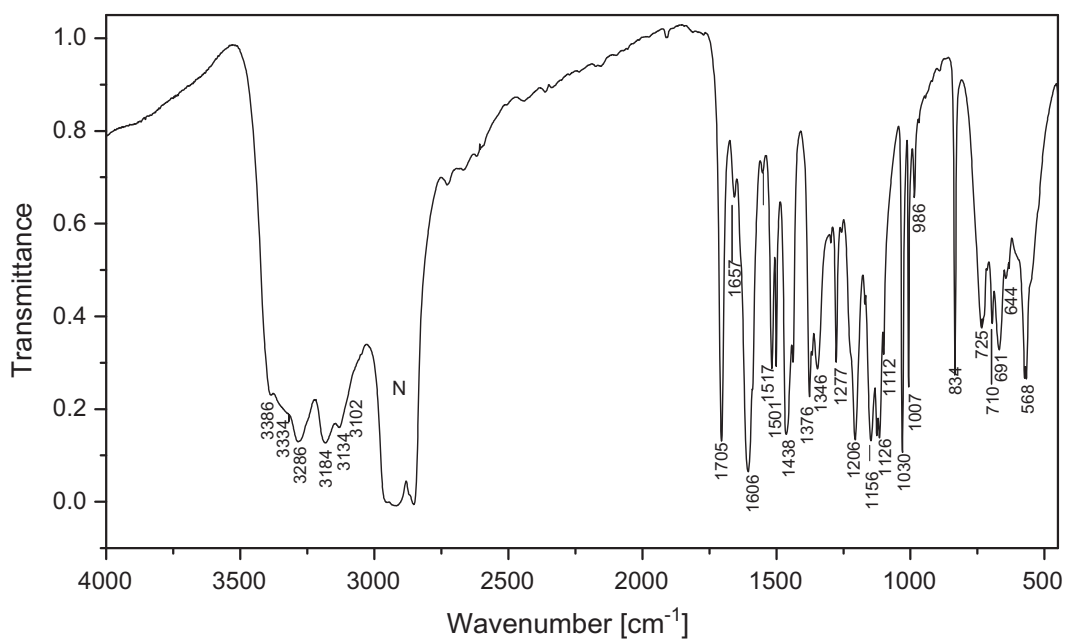

(a)

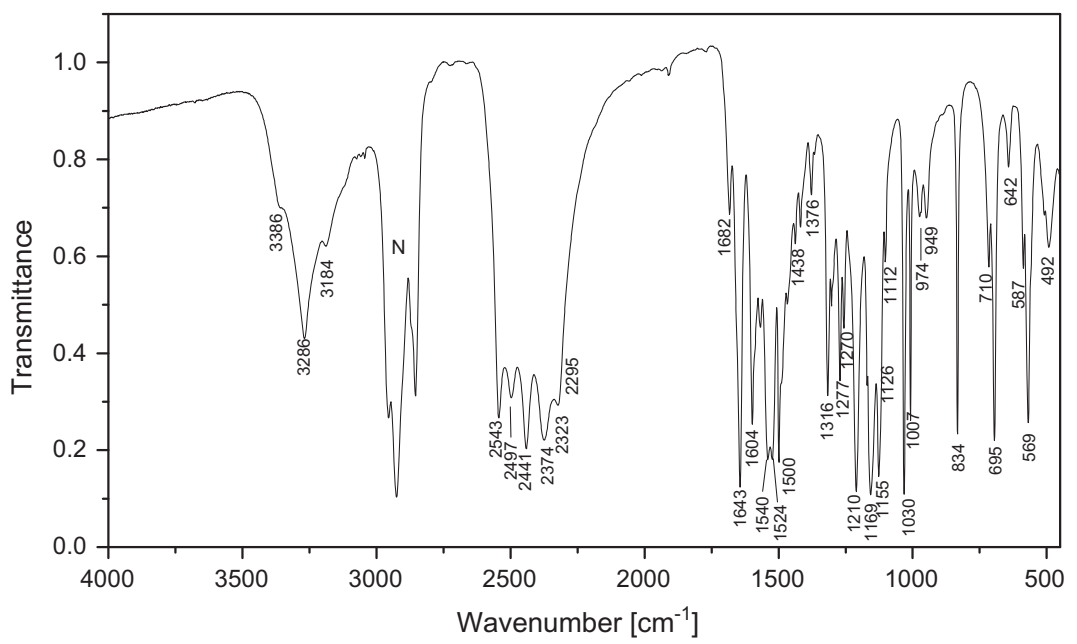

(b)

Fig. 4. IR-spectrum of 1-(diaminomethylene)thiouron-1-ium 4-hydroxybenzene-sulfonate (a) and its deuterated analogue (b).

The conformation of the 1-(diaminomethylene)thiouron-1-ium cation in the crystals is not strictly planar, but twisted. Both arms of the cation are oppositely rotated around the $\mathrm{C}-\mathrm{N}$ bonds involving the central $\mathrm{N} 1$ atom. The dihedral angle between the $\mathrm{N} 1 / \mathrm{C} 1 / \mathrm{S} 1 / \mathrm{N} 2$ and $\mathrm{N} 1 / \mathrm{C} 2 / \mathrm{N} 3 / \mathrm{N} 4$ planes is equal to $8.5(1)^{\circ}$. The dihedral angle in the present structure is significantly smaller than that in the crystal of neutral 1-(diaminomethylene)thiourea $\left(22.2(1)^{\circ}\right)$ [6]. The gas-phase conformation of the 1-(diaminomethylene) thiouron-1-ium cation as show the ab initio MO calculations is also twisted with similar dihedral angle of $6.2^{\circ}$ [8a]. A search in the Cambridge Structural Data Base (version 5.35, November 2013) [17] for structures containing 1-(diaminomethylene)thiouro n-1-ium cation yield 23 structures, in which the cation exhibits also twisted conformation. The 1-(diaminomethylene)thiouro n-1-ium cation twisting may differ $\left(\sim 1.4^{\circ}\right)$ for 1 -(diaminomethyle ne)thiouron-1-ium perchlorate [8b] to 22.9(1) for 1-(diaminomethylene)thiouron-1-ium chloride [8a] and depends on the anions and is undoubtedly dependent on the hydrogen bonding system formed with the oppositely charged units. Protonation of the neutral 1-(diaminomethylene)thiourea molecule causes a decrease of the steric effect of the lone pair of electron at the central N1 atom and reduce the twisting angle between the arms of the 1-(diamino methylene)thiouron-1-ium cation, when compared with that of neutral molecule. The $\mathrm{C} 1-\mathrm{S} 1$ bond (Table 2 ) is slightly longer than the typical $\mathrm{C}=\mathrm{S}$ double bond as observed in the thioformaldehyde $\mathrm{CH}_{2} \mathrm{C}=\mathrm{S}(1.6019(8) \AA)$ [18], which represents $100 \%$ double-bond character. The three $\mathrm{C}-\mathrm{N}$ bonds linking the amine groups are shorter than the $\mathrm{C}-\mathrm{N}$ bonds involving the central $\mathrm{N} 1$ atom (Table 2). The planarity of the amine groups points to the $s p^{2}$ hybridisation of the orbitals on the amine nitrogen atoms and the lone pair of electron localised on the $p$ orbital. Therefore the partial delocalisation of the lone pair on $p$ orbital of the amine groups and of the $\pi$ bond of the double $\mathrm{C} 1=\mathrm{S} 1$ and $\mathrm{C} 2=\mathrm{N} 1$ bonds is possible and leads to shortening of other $\mathrm{C}-\mathrm{N}$ bonds linking the amine groups and to the elongation of the $\mathrm{C} 1=\mathrm{S} 1$ and $\mathrm{C} 2=\mathrm{N} 1$ bonds (Table 2 ).

The geometrical parameters of the anionic part of the crystal, i.e. 4-hydroxybenzenesulfonate(-) do not deviate significantly from the reported values in the other structures containing this anion [17]. The hydroxyl group of 4-hydroxybenzenesulfonate(-) is coplanar with the aromatic ring, whereas the $\mathrm{SO}_{3}^{-}$group is oriented with the $\mathrm{O} 2$ atom almost perpendicular to the ring plane $\left(\mathrm{O} 2-\mathrm{S} 2-\mathrm{C} 3-\mathrm{C} 4\right.$ torsion angle is equal to $\left.-92.0(1)^{\circ}\right)$. The $\mathrm{C}-\mathrm{S}$ bond linking the $\mathrm{SO}_{3}^{-}$group with a distance of $1.7579(14) \AA$ is typical for the $\mathrm{C}\left(s p^{2}\right)-\mathrm{S}$ bond [19].

The 4-hydroxybenzenesulfonate(-) anions related by a screw axis $(2$ parallel to $b$ ) are linked head to tail forming $\mathrm{O}-\mathrm{H} \cdots \mathrm{O}$ hydrogen 


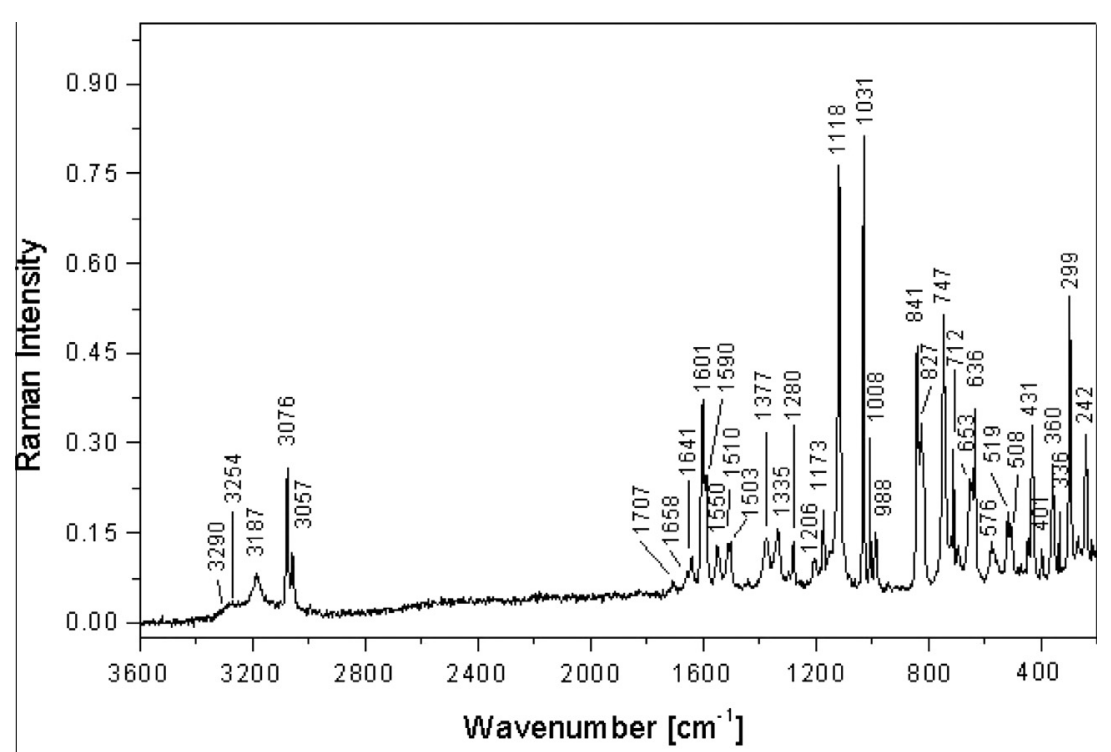

(a)

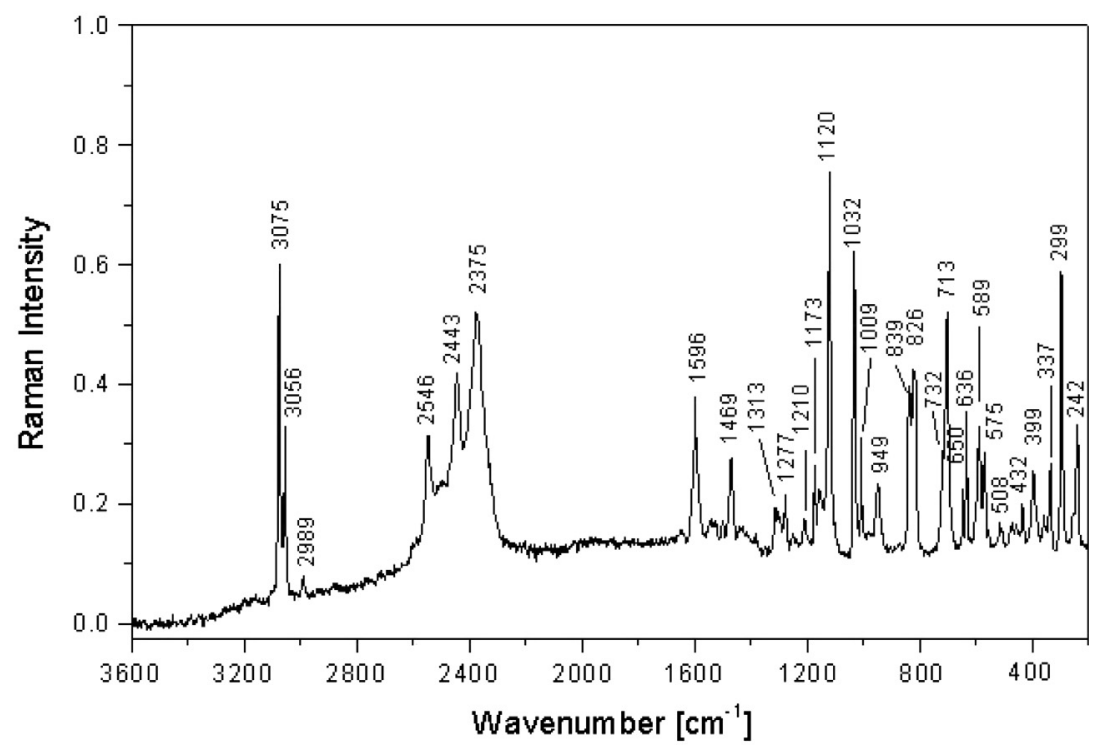

(b)

Fig. 5. Raman spectrum of 1-(diaminomethylene)thiouron-1-ium 4-hydroxybenzene-sulfonate (a) and its deuterated analogue (b).

bonded zigzag chains along [010] direction (Fig. 2a). The one-dimensional arrangement of 4-hydroxybenzenesulfonate(-) anions form ribbon with assistance 1-(diaminomethylene)thiouro n-1-ium cations and the $\mathrm{N}-\mathrm{H} \cdots \mathrm{O}$ hydrogen bonds (Fig. 2b). Within the ribbon the hydrogen bonded 1-(diaminomethylene) thiouron-1-ium 4-hydroxybenzenesulfonate(-) molecules are related by the screw axis $2_{1}$ and translation. Neighbouring, inversion related ribbons are combined via $\mathrm{N}-\mathrm{H}$...S hydrogen bonds with a graph of $\mathrm{R}_{2}^{2}(8)$ (Table 3 ) to form two-dimensional supramolecular structure parallel to the (104) plane (Fig. 3a). The importance of such interactions has been questioned [20]. However, the D-H $\cdots$ S interactions $(\mathrm{D}=$ donor) are important in the biological systems due to presence of high content of $\mathrm{S}$ atom in biological molecules. In addition, the $\mathrm{N}-\mathrm{H} \ldots \mathrm{S}$ interactions have been utilised for design supramolecular arrangement of thiourea derivatives [21]. Therefore, such $\mathrm{N}-\mathrm{H} \cdots \mathrm{S}$ interactions seem to be important in the present structures (Table 3), where the formation of the intramolecular $\mathrm{N}-\mathrm{H} \cdots \mathrm{S}$ interactions is favoured by the six-membered hydrogen-bonded ring with a graph of $S(6)$ and the intermolecular eight-membered hydrogen-bonded ring with a graph of $\mathrm{R}_{2}^{2}(8)$; the presence of $\mathrm{C}=\mathrm{S}$ bond makes it some resonance-assisted stabilisation. The possibility of resonance-induced hydrogen bond ring formation with the $S$ atom of a $\mathrm{C}=\mathrm{S}$ group with $\mathrm{N}$ substituents has been mentioned by Allen et al. [22]. However, in this structure the hydrogen bonds involving the $\mathrm{S}$ atom seem to be driven by the stronger $\mathrm{N}-\mathrm{H} \ldots \mathrm{O}$ and $\mathrm{O}-\mathrm{H} \ldots \mathrm{O}$ hydrogen bonds (Table 3). Neighbouring, N-H.S hydrogen bonding two-dimensional layers related via translation along the $a$-axis interact mainly via van der Waals forces, since there are no directional interactions between the successive layers. Transitionally related along $a$-axis aromatic rings of 4-hydroxybenzenesulfonate(-) anions are overlapped (Fig. 3b). The distance between the ring centroids $C_{g}(x, y, z) \cdots C_{g}(1+x, y z)$ is 5.643(1) A. This value is too large for the effective $\pi-\pi$ interactions 
Table 5

FT-IR spectral data for 1-(diaminomethylene)thiouron-1-ium 4-hydroxy-benzenesulfonate and its deuterated analogue.

\begin{tabular}{|c|c|c|c|}
\hline $\begin{array}{l}\text { Protiated, v } \\
\mathrm{cm}^{-1}\end{array}$ & $\begin{array}{l}\text { Deuterated, } v \\
\mathrm{~cm}^{-1}\end{array}$ & Assignment & $\begin{array}{l}\text { Isotopic } \\
\text { ratio }\end{array}$ \\
\hline $3386 s$ & $2543 \mathrm{~s}$ & $\begin{array}{l}v_{a}\left(N_{2}\right) \text { or } v_{a}\left(N_{2}\right) \text { asym stretch, } \\
v(\mathrm{OH}) \text { or } v(O D)\end{array}$ & 1.331 \\
\hline $3334 s$ & $2497 s$ & $v_{a}\left(N_{2}\right)$ or $v_{a}\left(N_{2}\right)$ asym stretch & 1.335 \\
\hline $3286 s$ & $2441 \mathrm{~s}$ & $v_{a}\left(N_{2}\right)$ or $v_{a}\left(N_{2}\right)$ asym stretch & 1.346 \\
\hline $3184 s$ & $2374 s$ & $v_{s}\left(N_{2}\right)$ or $v_{s}\left(N_{2}\right)$ sym stretch & 1.341 \\
\hline $3134 s$ & $2323 m$ & $v_{\mathrm{s}}\left(\mathrm{NH}_{2}\right)$ or $\mathrm{v}_{\mathrm{s}}\left(\mathrm{ND}_{2}\right)$ sym stretch & 1.349 \\
\hline $3102 s$ & $2295 \mathrm{~m}$ & $v_{\mathrm{s}}\left(\mathrm{NH}_{2}\right)$ or $\mathrm{v}_{\mathrm{s}}\left(\mathrm{ND}_{2}\right)$ sym stretch & 1.352 \\
\hline \multicolumn{4}{|c|}{ 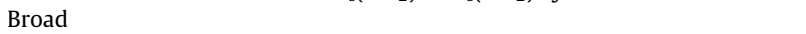 } \\
\hline $\begin{array}{l}\text { Band } \\
\qquad 2800\end{array}$ & $\sim 2200$ & $\begin{array}{l}\mathrm{N}-\mathrm{H} \cdots \mathrm{O} \text { or } \mathrm{N}-\mathrm{D} \cdots \mathrm{O} \text { hydrogen } \\
\text { bonds }\end{array}$ & \\
\hline $1705 s$ & $1210 s$ & Imine bond stretch & 1.409 \\
\hline $1657 w$ & $\begin{array}{l}\text { 1682w, } \\
1643 s\end{array}$ & & \\
\hline 1606vs & $1604 \mathrm{~s}$ & $\mathrm{~N}-\mathrm{C}-\mathrm{N}$ bend + ring def. & \\
\hline $1517 \mathrm{~m}$ & $1540 s, 1524 s$ & & \\
\hline $1501 \mathrm{~m}$ & $1500 s$ & & \\
\hline $1438 s$ & 1438w & $v(C-N)$ & \\
\hline $1376 \mathrm{~m}$ & 1376w & $\gamma(\mathrm{C}-\mathrm{C})$ overlapped with nujol & \\
\hline $1346 \mathrm{~m}$ & 1316w & & \\
\hline $1277 \mathrm{~m}$ & $1277 \mathrm{~m}$ & $\mathrm{v}_{\mathrm{a}}\left(\mathrm{SO}_{3}\right)$ asym stretch & \\
\hline \multicolumn{4}{|l|}{$1206 s$} \\
\hline $1156 s$ & $1155 \mathrm{~s}$ & $v_{a}\left(\mathrm{SO}_{3}\right)$ asym stretch & \\
\hline $1126 s$ & 1126w & $v_{a}\left(\mathrm{SO}_{3}\right)$ asym stretch & \\
\hline $1118 \mathrm{~m}$ & $1112 w$ & $v_{\mathrm{s}}\left(\mathrm{SO}_{3}\right)$ sym stretch & \\
\hline 1030s & $1030 \mathrm{~s}$ & $v_{\mathrm{s}}\left(\mathrm{SO}_{3}\right)$ sym stretch & \\
\hline $1007 \mathrm{~m}$ & $1007 \mathrm{~m}$ & $\begin{array}{l}v_{s}\left(\mathrm{SO}_{3}\right) \text { sym stretch., overlapped } \\
\text { with } \gamma(\mathrm{C}-\mathrm{N})\end{array}$ & \\
\hline $986 w$ & $974 w, 949 w$ & $v(C-C)$ & \\
\hline $834 \mathrm{~m}$ & $834 s$ & $\mathrm{C}-\mathrm{C}-\mathrm{C}$ def. of phenol ring & \\
\hline \multicolumn{4}{|l|}{$725 m$} \\
\hline $710 \mathrm{~m}$ & $710 \mathrm{~m}$ & $v(C=S)$ & \\
\hline $691 \mathrm{~m}$ & $695 s$ & $\mathrm{C}-\mathrm{C}-\mathrm{O}$ def. of phenol ring & \\
\hline \multirow[t]{2}{*}{$644 m$} & $642 w$ & & \\
\hline & $587 \mathrm{~m}$ & & \\
\hline \multirow[t]{2}{*}{$568 \mathrm{~m}$} & $569 \mathrm{~s}$ & $\begin{array}{l}\text { Skeletal } \mathrm{C}-\mathrm{N}-\mathrm{C}, \mathrm{N}-\mathrm{C}-\mathrm{N}, \mathrm{SO}_{3} \\
\text { asym. def. }\end{array}$ & \\
\hline & 492w & & \\
\hline
\end{tabular}

Weak, w; medium, m; strong, s; very, v.

between the $\pi$-cloud of the aromatic rings of the 4-hydroxybenzenesulfonate(-) anions.

Molecular orbital calculations with geometry optimisation and the energies of possible hydrogen-bonding interactions between 1-(diaminomethylene)-thiouron-1-ium cation and 4-hydroxybenzenesulfonate anion are fall into three groups. The first with the lower energy is observed for hydrogen bonded units $a$ and $b$ (Scheme 2) with graphs of $\mathrm{R}_{2}^{1}(6)$ and $\mathrm{R}_{2}^{2}(8)$. However, the unit a with the lowest energy represents the most possible hydrogen-bonding interactions between 1-(diaminomethyle ne)-thiouron-1-ium cation and 4-hydroxybenzenesulfonate anion and therefore it is observed in the structure of the crystal (see Figs. $2 \mathrm{~b}$ and $3 \mathrm{a}$ ). The other hydrogen bonded unit $\mathrm{b}$ with $\mathrm{R}_{2}^{1}(6)$ and $R_{2}^{2}(8)$ graphs with comparable energy to the unit a (with $\Delta E=2.03 \mathrm{~kJ} \mathrm{~mol}^{-1}$ ) is not present in the structure of the crystal. The second group with intermediate energy was found for the hydrogen bonded units with a graph of $\mathrm{R}_{2}^{2}(8)$ (c, $d$ and $\mathrm{e}$ in Scheme 2). Within these three units with comparable energy only one of them (hydrogen bonded unit e) is observed in the structure of the crystal (see Figs. 1 and $2 b$ and 3a). The third group of hydrogen bonding interactions with significantly greater energy is found for the units with a graph of $\mathrm{R}_{2}^{2}(6)$ formed by donation to the sulfonate group from only one amine group (units f, $\mathrm{g}$ and $\mathrm{h}$ in Scheme 2) and they are no found in the crystal. The difference $(\Delta E)$ between the energy of the most stable unit a and the energy of other hydrogen bonded units are listed in Table 4.
Table 6

Raman spectral data for 1-(diaminomethylene)thiouron-1-ium 4-hydroxy-benzenesulfonate and its deuterated analogue.

\begin{tabular}{|c|c|c|c|}
\hline $\begin{array}{l}\text { Protiated v } \\
\mathrm{cm}^{-1}\end{array}$ & $\begin{array}{l}\text { Deuterated } \\
v \mathrm{~cm}^{-1}\end{array}$ & Assignment & $\begin{array}{l}\text { Isotopic } \\
\text { ratio }\end{array}$ \\
\hline 3290w & $2546 \mathrm{~m}$ & $v_{a}\left(N_{2}\right)$ or $v_{a}\left(N_{2}\right)$ asym stretch & 1.292 \\
\hline $3254 w$ & $2437 \mathrm{~m}$ & $v_{a}\left(N_{2}\right)$ or $v_{a}\left(N_{2}\right)$ asym stretch & 1.335 \\
\hline $3187 w$ & $\begin{array}{l}2375 \text { s; and } \\
2355 \text { sh }\end{array}$ & $\begin{array}{l}v_{s}\left(\mathrm{NH}_{2}\right) \text { or } v_{\mathrm{s}}\left(\mathrm{ND}_{2}\right) \text { sym stretch and } \\
\mathrm{O}-\mathrm{H}(\mathrm{D}) \ldots \mathrm{O} \text { stretch }\end{array}$ & 1.342 \\
\hline $3076 \mathrm{~m}$ & $3075 s$ & $\mathrm{C}-\mathrm{H}$ stretch & \\
\hline $3057 w$ & $3056 \mathrm{~m}$ & $\mathrm{C}-\mathrm{H}$ stretch & \\
\hline $1706 v w$ & 1210w & Imine bond stretch & 1.399 \\
\hline \multicolumn{4}{|l|}{$1658 w$} \\
\hline \multicolumn{4}{|l|}{$1641 w$} \\
\hline $1601 \mathrm{~m}$ & & $\mathrm{~N}-\mathrm{C}-\mathrm{N}$ bend + ring def. & \\
\hline 1590w & $1596 \mathrm{~m}$ & $\mathrm{~N}-\mathrm{C}-\mathrm{N}$ bend + ring def. & \\
\hline \multicolumn{4}{|l|}{$1550 w$} \\
\hline $1510 w$ & $1469 w$ & & \\
\hline \multicolumn{4}{|l|}{$1403 w$} \\
\hline $1377 w$ & & $\gamma(\mathrm{C}-\mathrm{C})$ & \\
\hline 1336w & $1313 w$ & & \\
\hline $1280 w$ & $1277 w$ & $\mathrm{v}_{\mathrm{a}}\left(\mathrm{SO}_{3}\right)$ asym stretch & \\
\hline \multicolumn{4}{|l|}{$1206 w$} \\
\hline $1173 w$ & $1173 w$ & $\mathrm{v}_{\mathrm{a}}\left(\mathrm{SO}_{3}\right)$ asym stretch & \\
\hline 1118vs & 1120vs & $v_{\mathrm{s}}\left(\mathrm{SO}_{3}\right)$ sym stretch & \\
\hline $1031 \mathrm{vs}$ & $1032 s$ & $v_{s}\left(\mathrm{SO}_{3}\right)$ sym stretch & \\
\hline $1008 w$ & $1009 \mathrm{~m}$ & $\mathrm{v}_{\mathrm{s}}\left(\mathrm{SO}_{3}\right)$ sym stretch & \\
\hline $988 w$ & $949 w$ & $v(C-C)$ & \\
\hline $841 \mathrm{~m}$ & $839 \mathrm{~m}$ & $\begin{array}{l}\mathrm{C}-\mathrm{C}-\mathrm{C} \text { def. out of plane of phenol } \\
\text { ring }\end{array}$ & \\
\hline $827 \mathrm{~m}$ & $826 \mathrm{~m}$ & Ring-sextant out-of-plane bend & \\
\hline $747 \mathrm{~s}$ & $732 w$ & & \\
\hline $712 w$ & $713 \mathrm{~m}$ & $v(C=S)$ & \\
\hline $653 w$ & $650 w$ & $\mathrm{C}-\mathrm{C}-\mathrm{O}$ def. of phenol ring & \\
\hline $636 \mathrm{~m}$ & $636 \mathrm{~m}$ & & \\
\hline $576 w$ & $589 \mathrm{~m}$ & $\begin{array}{l}\text { Skeletal } \mathrm{C}-\mathrm{N}-\mathrm{C}, \mathrm{N}-\mathrm{C}-\mathrm{N}, \mathrm{SO}_{3} \text { asym. } \\
\text { def. }\end{array}$ & \\
\hline \multicolumn{4}{|l|}{$519 w$} \\
\hline $508 w$ & $508 w$ & & \\
\hline $431 \mathrm{~m}$ & $432 w$ & $\mathrm{SO}_{3}$ sym. def. & \\
\hline $401 w$ & $399 w$ & & \\
\hline \multicolumn{4}{|l|}{$360 w$} \\
\hline $336 w$ & $337 w$ & & \\
\hline $299 s$ & $299 s$ & & \\
\hline $242 \mathrm{~m}$ & $242 \mathrm{~m}$ & & \\
\hline
\end{tabular}

Weak, w; medium, m; strong, s; very, v; shoulder, sh.

The FT-IR spectra of 1-(diaminomethylene)thiouron-1-ium 4-hydroxybenzenesulfonate and its deuterated analogue are shown in Fig. 4a and b, respectively, whereas the Raman spectra are shown in Fig. 5a and b. The title compound has several functional and skeletal groups such as three $\mathrm{NH}_{2} \mathrm{C}=\mathrm{S}, \mathrm{C}-\mathrm{N}-\mathrm{C}$, $\mathrm{N}-\mathrm{C}-\mathrm{N}$ and $\mathrm{N}-\mathrm{C}-\mathrm{S}$ groups in the cation and the $\mathrm{SO}_{3}^{-}, \mathrm{OH}$ and the six-membered aromatic ring in the anion. The bands corresponding to the vibration of these groups were identified with the aid of infrared correlation charts [23]. The IR spectra of neutral 1-(diaminomethylene)thiourea [8g] and of $p$-phenolsulfonic acid [24] will be helpful for assignment of the bands observed in the spectrum of the title compound. A careful inspection of the IR spectrum (Fig. 4a) shows medium-strong intensity bands in the spectral range of $3400-3100 \mathrm{~cm}^{-1}$. These bands can be attributed to the $\mathrm{OH}$ group of 4-hydroxybenzenesulfonate(-) anion and to the asymmetric and symmetric stretching of three $\mathrm{NH}_{2}$ groups of the 1-(diaminomethylene)thiouron-1-ium cation. These bands, as expected, are shifted in the IR spectrum of deuterated analogue (Fig. 4b) to the spectral region of $2550-2250 \mathrm{~cm}^{-1}$. The isotopic ratio between 1.331 and 1.352 points on the vibration anharmonicity. The strong band at $2543 \mathrm{~cm}^{-1}$ should be attributed to the OD and the other to the asymmetric and symmetric stretching of three $\mathrm{ND}_{2}$ groups. In the spectrum of deuterated analogue (Fig. 4b), the bands of the of the protiated compound with significantly lower intensities are observed. Theses bands resulting from 
the equilibrium between protiated and deuterated analogue and point on the not fully exchange of $\mathrm{H}$ to $\mathrm{D}$. The degree of deuteration is estimated to $\sim 75 \%$. In the Raman spectrum (Fig. 5a) $v\left(\mathrm{NH}_{2}\right)$ stretching vibrations appear in the $3300-3000 \mathrm{~cm}^{-1}$ region as a very weak ones, while in the Raman spectrum (Fig. 5b) of deuterated analogue these bands, as expected, are shifted to the region of $2550-2350 \mathrm{~cm}^{-1}$ (with the isotopic ratio of $1.292-1.352$ ). The $v\left(\mathrm{NH}_{2}\right)$ stretching vibrations bands are overlapped with the vibration stretching of the $\mathrm{OH}$ group of 4-hydroxybenzenesulfonate(-) anion that form $\mathrm{O}-\mathrm{H}(\mathrm{D}) \ldots \mathrm{O}$ hydrogen bond forming head-to-tail hydrogen bonded chain (Fig. 2a). In addition in this spectral region the two narrow medium-strong bands at 3075 and $3057 \mathrm{~cm}^{-1}$ are observed in the Raman spectrum of both, protiated and deuterated, samples and are assigned to the $\mathrm{C}-\mathrm{H}$ stretching of the 4-hydroxybenzenesulfonate anion. The strong narrow band at $1705 \mathrm{~cm}^{-1}$ in the spectrum of protiated compound is assigned to the stretching of imine group of the 1-(diaminomethylene)thiouro $\mathrm{n}$-1-ium cation, since it is not observed in the IR spectrum of neutral 1-(diaminomethylene)thiourea [8g]. A similar band is observed in some imines and their salts [25]. In addition, the band of imine group of the deuterated sample is shifted, as expected, to the $1210 \mathrm{~cm}^{-1}$. Its Raman counterpart is observed at $1707 \mathrm{~cm}^{-1}$ in spectrum of protiated sample as a weak band (Fig. 5a) and at $1210 \mathrm{~cm}^{-1}$ in the deuterated analogue (Fig. 5b). The isotopic ratio for the band of imine group is equal to $\sim 1.4$ and points on the almost harmonic vibration. The X-ray data reveal that the all amine groups of the 1 -(diaminomethylene)thiouron-1-ium cation are involved in two types of hydrogen bonds: $\mathrm{N}-\mathrm{H} \cdots \mathrm{O}$ with $\mathrm{N} \ldots \mathrm{O}$ distance between $2.880(2) \AA$ and $3.018(2) \AA$, and $\mathrm{N}-\mathrm{H} \cdots \mathrm{S}$ with $\mathrm{N} \cdots \mathrm{S}$ of 2.908(2) $\AA$ and 3.414(2) $\AA$ in intra- and intermolecular interaction, respectively. This reveals as a shoulder around $\sim 2800 \mathrm{~cm}^{-1}$ that is shifted to $\sim 2200 \mathrm{~cm}^{-1}$ in the spectrum of deuterated analogue. In addition the broad band in the region of $1400-1100 \mathrm{~cm}^{-1}$ that overlapped with the other bands points the presence of the $\mathrm{N}-\mathrm{H} \ldots \mathrm{O}$ hydrogen bonds. In the spectrum of $p$-phenolsulfonic acid, three very strong bands at 1288, 1172 and $1125 \mathrm{~cm}^{-1}$ are present [24], which originate from asymmetric stretching vibrations of the $\mathrm{SO}_{3}$ group. For isolated $\mathrm{SO}_{3}$ group with $C_{3 v}$ symmetry one expected four normal modes: $v_{3}(\mathrm{E})=1291 \mathrm{~cm}^{-1} \quad$ (asym. stretch), $v_{1}\left(\mathrm{~A}_{1}\right)=1053 \mathrm{~cm}^{-1} \quad$ (sym. stretch), $v_{4}(\mathrm{E})=551 \mathrm{~cm}^{-1}$ (asym. def.) and $v_{2}\left(\mathrm{~A}_{2}\right)=535 \mathrm{~cm}^{-1}$ (sym. def.). In the present structure, due to lowering of the symmetry of the $\mathrm{SO}_{3}$ group from the ideal $C_{3 v}$ symmetry, the length of $\mathrm{S}-\mathrm{O}$ bonds ranging from $1.4438(11)$ to $1.4643(11) \AA$, and the crystal field effect, the splitting can be observed for the double degenerated $v_{3}$ and $v_{4}$ modes. Thus the bands of asymmetric stretching of $\mathrm{SO}_{3}$ group are observed at the 1277, 1156 and $1126 \mathrm{~cm}^{-1}$, whereas the strong narrow bands at 1030 and $1007 \mathrm{~cm}^{-1}$ originate from symmetric stretching of $\mathrm{SO}_{3}$ group in the spectrum of protiated and deuterated analogue (Fig. $4 \mathrm{a}$ and b). The respective asymmetric and symmetric stretching of $\mathrm{SO}_{3}$ group are also observed in the Raman spectrum of protiated and deuterated analogue (Fig. 5a and b) at, as expected, almost the same wavenumbers. The strong IR band at $834 \mathrm{~cm}^{-1}$ originates from the $\mathrm{C}-\mathrm{C}-\mathrm{C}$ deformation of the aromatic ring, and the band at $695 \mathrm{~cm}^{-1}$ can be attributed to the $\mathrm{C}-\mathrm{C}-\mathrm{O}$ of the phenol moiety. Similar bands are also observed in the Raman spectrum of protiated and deuterated samples. These bands with similar wavenumbers are also observed in the spectrum of melaminium $p$-phenolsulfonate [24]. The band of the $\mathrm{C}=\mathrm{S}$ group of 1 -(diamino methylene)thiouron-1-ium cation is observed at $\sim 716 \mathrm{~cm}^{-1}$ in both $\mathrm{H}$ and $\mathrm{D}$ samples, since a similar band is observed in the spectrum of other salts containing 1-(diaminomethylene)thiouro $\mathrm{n}$-1-ium cation $[8 \mathrm{~g}-\mathrm{j}, 9]$ as well as in the spectrum of thiourea and several thiourea metal complexes, in which the $v(\mathrm{C}=\mathrm{S})$ band is observed in the range of $720-700 \mathrm{~cm}^{-1}[22,26]$. The $v(\mathrm{C}=\mathrm{S})$ band is also observed in the Raman spectrum of protiated and deuterated samples at almost the same wavenumber. The relatively strong band at $\sim 568 \mathrm{~cm}^{-1}$ observed in the infrared spectrum of protiated and deuterated analogue having a weak Raman counterpart at $\sim 576 \mathrm{~cm}^{-1}$ was attributed to $\mathrm{SO}_{3}$ deformation, which is overlapped with the $\mathrm{C}-\mathrm{N}-\mathrm{C}, \mathrm{N}-\mathrm{C}-\mathrm{N}$ skeletal vibrations. The observed IR and Raman frequencies of the most prominent bands for protiated and deuterated sample are listed in Tables 5 and 6.

\section{Conclusion}

This study confirms the usefulness of 1-(diaminomethylene) Othiourea as a building block in the crystal engineering and demonstrates its interaction with $p$-phenolsulfonic acid forming of extended supramolecular structure. Head to tail $\mathrm{O}-\mathrm{H} \cdots \mathrm{O}$ hydrogen bonded interactions between $p$-phenolsufonate anions lead to formation of zigzag chains that with assistance of 1-(diami nomethylene)thiouron-1-ium cations forming ribbons. The ribbons interact each other via $\mathrm{N}-\mathrm{H} \ldots \mathrm{S}$ hydrogen bonds forming two-dimensional supramolecular architecture. Supramolecular architecture is formed by the two relatively stable hydrogen bonding interactions between the 1-(diaminomethylene)-thiouro n-1-ium cation and 4-hydroxybenzenesulfonate anion; one with graphs of $R_{2}^{1}(6)$ and $R_{2}^{2}(8)$ and the other with a graph of $R_{2}^{2}(8)$. Comparison of the IR spectra of protiated 1-(diaminomethylene) thiouron-1-ium 4-hydroxybenzenesulfonate with its deuterated analogue clearly evidenced marked differences in the regions of vibrations of the amine, imine and hydroxyl groups as well as in the region of the hydrogen bonds (see Table 6).

\section{Appendix A. Supplementary material}

Additional material comprising full details of the X-ray data collection and final refinement parameters including anisotropic thermal parameters and full list of the bond lengths and angles have been deposited with the Cambridge Crystallographic Data Center in the CIF format as supplementary publications no. CCDC 1043925. Copies of the data can be obtained free of charge on the application to CCDC, 12 Union Road, Cambridge, CB21EZ, UK, (fax: (+44) 1223-336-033; email: deposit@ccdc.cam.ac.uk).

Supplementary data associated with this article can be found, in the online version, at http://dx.doi.org/10.1016/j.molstruc.2015.04. 037.

\section{References}

[1] (a) G.R. Desiraju, Crystal Engineering. The Design of Organic Solids, Elsevier, Amsterdam, the Nederlands, 1989;

(b) J.M. Lehn, Supramolecular Chemistry: Concepts and Perspectives, VCH, Weinheim, 1995;

(c) G.R. Desiraju, Perspectives in Supramolecular Chemistry, Vol. 2, Wiley, Chichester, U.K, 1996;

(d) G.R. Desiraju, J. Am. Chem. Soc. 135 (2013) 9952-9967.

[2] (a) C.B. Aakeröy, Acta Cryst. B53 (1997) 569-586;

(b) D. Braga, Chem. Commun. (2003) 2751-2754

(c) C.B. Aakeröy, J. Desper, H. Faluso, L. Hussain, L. Brock, N. Schultheiss, CrystEngComm 10 (2008) 1816-1821;

(d) C.B. Aakeröy, P. Chopade, C. Gasner, J. Desper, Chem. Commun. (2011) 4688-4690.

[3] (a) G.R. Desiraju, Chem. Commun. (1997) 1475-1482;

(b) J. Starbuck, N.C. Norman, A.G. Orpen, New J. Chem. 23 (1997) 969-972;

(c) D. Braga, F. Grepioni, Coord. Chem. Rev. 183 (1999) 19-41;

(d) A.M. Beatly, CrystEngComm. 3 (2001) 243-255;

(e) C. Janiak, Dalton Trans. (2003) 2781-2784;

(f) L. Brammer, Chem Soc. Rev. 33 (2004) 476-489;

(g) C.B. Aakeröy, D.J. Salomon, CrystEngComm. 7 (2005) 439-448;

(h) G.R. Desiraju, Angew. Chem. Int. Ed. 46 (2007) 8342-8356;

(i) C.B. Aakeröy, V.S. Panikkattu, B. DeHaven, J. Desoer, Cryst. Groth Des. 12 (2012) 2579-2587.

[4] (a) J.C. MacDonald, G.M. Withesides, Chem. Rev. 94 (1994) 2382-2420; (b) G.M. Whitesides, E.E. Simanek, J.P. Mathias, C.T. Seto, D. Chin, M. Mammen, 
D.M. Gordon, Acc. Chem. Res. 28 (1995) 37-44;

(c) G.R. Desiraju, Angew. Chem. Int. Ed. 34 (1995) 2311-2327;

(d) T. Steiner, Angew. Chem. Int. Ed. 48 (2002) 49-76;

(e) C.C. Seaton, K. Chadwick, G. Sadig, K. Guo, R.J. Davey, Cryst. Growth Des. 10 (2010) 726-733.

[5] (a) M.C. Etter, J. MacDonald, J. Bernstein, Acta Cryst. B46 (1990) 256-262;

(b) M.C. Etter, Acc. Chem. Res. 23 (1990) 120-126;

(c) M.C. Etter, J. Phys. Chem. 95 (1991) 4601-4610.

[6] J. Janczak, G.J. Perpetuo, Acta Cryst. C64 (2008) o114-0116.

[7] (a) K. Chakrabaty, S.P.S. Gupta, Indian J. Phys. A57 (1983) 205-209;

(b) K. Chakrabaty, T. Kar, S.P.S. Gupta, Acta Cryst. C46 (1990) 2065-2068;

(c) E. Doxiadi, R. Vilar, A.J.P. White, D.J. Williams, Polyhedron 22 (2003) 2991 2998;

(d) M. Hołyńska, M. Korabik, M. Kubiak, Polyhedron 29 (2010) 530-538.

[8] (a) G.J. Perpétuo, J. Janczak, Acta Cryst. C64 (2008) o264-0268;

(b) J. Janczak, G.J. Perpétuo, Acta Cryst. C64 (2008) 0330-0334;

(c) J. Janczak, G.J. Perpétuo, Acta Cryst. C65 (2009) o118-0120;

(d) M. Hołyńska, M. Kubiak, Acta Cryst. C64 (2008) o609-0612;

(e) M. Hołyńska, M. Kubiak, Acta Cryst. C65 (2009) o191-0194;

(f) M. Hołyńska, M. Kubiak, Acta Cryst. C65 (2009) 0410-0413;

(g) J. Janczak, G.J. Perpétuo, J. Mol. Struct. 975 (2010) 166-172;

(h) J. Janczak, G.J. Perpétuo, J. Mol. Struct. 988 (2011) 73-81;

(i) G.J. Perpétuo, J. Janczak, J. Mol. Struct. 1007 (2012) 74-80;

(j) G.J. Perpétuo, J. Janczak, J. Mol. Struct. 10541 (2013) 127-138.

[9] G.J. Perpétuo, J. Janczak, J. Mol. Struct. 1031 (2013) 14-21.

[10] CrysAlis CCD and CrysAlis Red, Version 171.32.6, Oxford Diffraction Poland, Wrocław, Poland (2006).

[11] (a) G.M. Sheldrick, SHELXS97, SHELXL97, Programs for Crystal Stuctures Solution and Refinement, University of Göttingen, Göttingen, Germany, 1997; (b) G.M. Sheldrick, Acta Cryst. A 64 (2008) 112-122.

[12] K. Brandenburg, H. Putz, DIAMOND Version 3.0, Crystal Impact GbR, Bonn, Germany, 2006.

[13] M.J. Frisch, G.W. Trucks, H.B. Schlegel, G.E. Scuseria, M.A. Robb, J.R. Cheeseman, G. Scalmani, V. Barone, B. Mennucci, G.A. Petersson, H. Nakatsuji, M. Caricato, X. Li, H.P. Hratchian, A.F. Izmaylov, J. Bloino, G. Zheng, J.L. Sonnenberg, M. Hada, M. Ehara, K. Toyota, R. Fukuda, J. Hasegawa, M. Ishida, T. Nakajima, Y. Honda, O. Kitao, H. Nakai, T. Vreven, J.A. Montgomery, Jr., J.E. Peralta, F. Ogliaro, M. Bearpark, J.J. Heyd, E. Brothers, K. N. Kudin, V.N. Staroverov, T. Keith, R.
Kobayashi, J. Normand, K. Raghavachari, A. Rendell, J.C. Burant, S.S. Iyengar, J. Tomasi, M. Cossi, N. Rega, J.M. Millam, M. Klene, J.E. Knox, J.B. Cross, V. Bakken, C. Adamo, J. Jaramillo, R. Gomperts, R.E. Stratmann, O. Yazyev, A.J. Austin, R. Cammi, C. Pomelli, J.W. Ochterski, R.L. Martin, K. Morokuma, V.G. Zakrzewski, G.A. Voth, P. Salvador, J.J. Dannenberg, S. Dapprich, A.D. Daniels, O. Farkas, J.B. Foresman, J.V. Ortiz, J. Cioslowski, D.J. Fox, Gaussian Inc, Wallingford CT, 2013. Gaussian09, Revision D.01, Programme, Gaussian Inc, Wallingford, CT, 2013.

[14] A.D. Becke, J. Chem. Phys. 104 (1996) 1040-1046.

[15] C. Lee, W. Yang, R.G. Parr, Phys. Rev. B 37 (1988) 785-789.

[16] B.G. Parr, W. Yang, Density-functional Theory of Atoms and Molecules, Oxford University Press, New York, 1989.

[17] F.H. Allen, Acta Cryst. B58 (2002) 380-388.

[18] D.R. Johnson, F.X. Powell, W.H. Kirchoff, J. Mol. Spectrosc. 39 (1971) 136-145.

[19] F.H. Allen, O. Kennard, D.G. Watson, L. Brammer, A.G. Orpen, R. Taylor, J. Chem. Soc., Perkin Trans. 2 (1989) S1-S19.

[20] G.Y. Bai, H.S. Ning, J. Simpson, X.Y. Qin, N. Li, Acta Cryst. E62 (2006) o456704568.

[21] F.H. Allen, C.H. Bird, R.S. Rowland, P.R. Raithby, Acta Cryst. B53 (1997) 696701.

[22] F.H. Allen, C.H. Bird, R.S. Rowland, P.R. Raithby, Acta Cryst. B53 (1997) 680695.

[23] (a) G. Socrates, Infrared Characteristic Group Frequencies, Wiley-Interscience, Chichester, U.K., 1980;

(b) G. Socrates, Infrared and Raman Characteristic Group Frequencies, 3rd ed., Wiley, New York, USA, 2001.

[24] M.K. Marchewka, Acta Chim. Slov. 50 (2003) 239-250.

[25] (a) J. Favrot, J.M. Leclercq, R. Roberge, S. Sandorfy, D. Vocelle, Photochem. Photobiol. 29 (1979) 99-108;

(b) J. Favrot, D. Vocelle, C. Sandrofy, Photochem. Photobiol. 30 (1979) 417-421.

[26] (a) P.A. Ajibade, N.H. Zulu, Int. J. Mol. Sci. 12 (2011) 7186-7198;

(b) S.M.S. Jambi, S.S. Kandil, J. Mater. Environ. Sci. 3 (2012) 591-604;

(c) P.M. Ushasree, R. Jayavel, C. Subramanian, P. Ramasamy, J. Cryst. Growth 197 (1999) 216-220;

(d) R. Rajasekaran, P.M. Ushasree, R. Jayavel, P. Ramasamy, J. Cryst. Growth 229 (2001) 563-567;

(e) R. Rajasekaran, R.M. Kumar, R. Jayavel, P. Ramasamy, J. Cryst. Growth 252 (2001) 317-327. 